Anales de Geografía de la Universidad Complutense ISSN: 0211-9803

http://dx.doi.org/10.5209/AGUC.53588

\title{
Adaptación del sector turístico al cambio climático en España. La importancia de las acciones a escala local y en empresas turísticas ${ }^{1}$
}

\author{
Jorge Olcina Cantos ${ }^{2}$; José Fernando Vera-Rebollo ${ }^{3}$ \\ Recibido: 29 de febrero del 2016 / Enviado a evaluar: 22 de mayo del 2016 / Aceptado: 18 de julio del 2016
}

Resumen. El $5^{\circ}$ Informe del IPCC (Panel Intergubernamental de Cambio Climático, 2014) señala que el turismo será una de las actividades económicas que mayores efectos negativos experimentará en las próximas décadas debido al calentamiento térmico del planeta. En España, el turismo es una fuente principal de ingresos y de creación de puestos de trabajo en su economía. De ahí que sea necesaria la puesta en marcha de medidas de adaptación a la nueva realidad climática que, en nuestro país, va a suponer cambios en el confort climático de los destinos e incremento de extremos atmosféricos. Frente a los planes de adaptación al cambio climático en la actividad turística, elaborados por los gobiernos estatal y regional, que apenas se han desarrollado en España, la escala local muestra interesantes ejemplos de acciones de adaptación al cambio climático, desarrolladas tanto por los municipios (energía, transporte, vivienda, planificación urbanística) como por la propia empresa turística (hoteles, campings, apartamentos). Medidas de ahorro de agua y luz, fomento del transporte público y de las energías limpias, creación de zonas verdes urbanas y adaptación a los extremos atmosféricos destacan como acciones de mitigación del cambio climático en los destinos turísticos principales de nuestro país.

Palabras clave: Turismo; cambio climático; medidas de adaptación; escala local.

1 Este trabajo se desarrolla parcialmente en el marco de los proyectos CSO2014-59193-R (MINECO) "Nuevos enfoques para la planificación y gestión del territorio turístico: conceptualización, análisis de experiencias y problemas. Definición de modelos operativos para destinos turísticos inteligentes" y "Usos y gestión de recursos hídricos no convencionales en el litoral de las regiones de Valencia y Murcia como estrategia de adaptación a la sequía" (CSO2015-65182-C2-2-P).

2 Universidad de Alicante.

E-mail: jorge.olcina@ua.es

3 Universidad de Alicante.

E-mail: jf.vera@ua.es 


\title{
[en] Adaptation of the tourism sector to climate change in Spain. The importance of action at local level and in tourism businesses
}

\begin{abstract}
The Fifth Assessment Report (AR5) (Intergovernmental Panel on Climate Change, 2014) indicates that tourism is one of the major economic activities that will experience negative effects in coming decades due to global warming. In Spain, tourism is a major source of income and creation of employment for the economy. Therefore, the implementation of measures to adapt to the new climate reality, that in our country will mean changes in climate comfort of destinations and increased atmospheric extremes events, is necessary. In contrast to plans to adapt to climate change in tourism activity developed by the state and regional governments, which have hardly been developed in Spain, local scale shows interesting examples of actions to adapt to climate change. These actions have been developed both by municipalities (energy, transport, housing, urban planning) as the tourist company (hotels, campsites, apartments). Water and electricity saving measures, promotion of public transport and clean energies, creating urban green areas and adaptation to atmospheric extremes stand out as the main mitigation measures to climate change in major tourist destinations in our country.
\end{abstract}

Key words: Tourism; climate change; adaptation measures; local scale.

\section{[fr] Adaptation du secteur du tourisme au changement climatique en Espagne. L'importance de l'action au niveau local et dans les entreprises touristiques}

Résumé. Le cinquième rapport du GIEC (Groupe d'experts intergouvernemental sur les changements climatiques, 2014) note que le tourisme est l'une des principales activités économiques qui connaîtront des effets négatifs au cours des prochaines décennies en raison du réchauffement thermique. En Espagne, le tourisme est une source majeure de revenus et de création d'emplois dans l'économie. D'où la mise en œuvre de mesures visant à adapter à la nouvelle réalité climatique que dans notre pays, se traduira par des changements dans le confort climatique des destinations et une augmentation des extrêmes atmosphériques nécessaires. Face aux plans d'adaptation au changement climatique dans l'activité touristique développée par les gouvernements nationaux et régionaux, qui ont à peine été développées en Espagne, à l'échelle locale montre des exemples intéressants de mesures d'adaptation aux changements climatiques, mis au point par les deux municipalités ( énergie, les transports, le logement, la planification urbaine) et par la société touristique elle-même (hôtels, campings, appartements). Enregistrement des mesures et de l'eau, la promotion des transports publics et de l'énergie propre, la création d'espaces verts urbains et l'adaptation aux extrêmes atmosphériques se distinguent comme l'atténuation des changements climatiques dans les principales destinations touristiques dans notre pays.

Mots clés: Tourisme; changement climatique; mesures d'adaptation; niveau local.

Cómo citar. Olcina Cantos, J. y Vera-Rebollo, J.F. (2016): Adaptación del sector turístico al cambio climático en España. La importancia de las acciones a escala local y en empresas turísticas. Anales de Geografía de la Universidad Complutense, 36(2), 321-349.

Sumario. 1. Introducción y contexto. 2. Impacto del cambio climático en España y sus efectos en las áreas turísticas litorales. 3. Experiencias de adaptación al cambio climático en municipios turísticos del litoral mediterráneo español. 4. La acciones de adaptación al cambio climático en el ámbito empresarial turístico. 5. Conclusiones. 6. Bibliografía. 


\section{Introducción y contexto}

La investigación sobre los efectos del cambio climático en la actividad turística es clave para el diseño y puesta en marcha de medidas de mitigación y adaptación (Olcina y Vera, 2016). En España, hasta el momento presente, se han abordado políticas de reducción del cambio climático de forma general, sin conocer realmente los efectos que puede tener el calentamiento térmico en los espacios turísticos y, por tanto, sin adaptar las medidas a la realidad concreta de esta actividad económica.

Para la fachada mediterránea española, que concentra el 50\% de la llegada anual de turistas a nuestro país, Olcina y Miró (2016), a partir de la aplicación del índice de Confort Climático de Mieczkowski (TCI) y su proyección hacia final del siglo XXI, han señalado que los efectos del calentamiento térmico planetario obligarán a modificar los calendarios de temporadas altas de esta actividad económica, en una planificación a largo plazo que no tiene necesariamente que resultar negativa en términos económicos. De hecho, la posible disminución de turistas en los meses de julio y agosto, debido a la pérdida de confort climático en el período central del verano, se verá compensada con la ganancia de dicho confort en los meses de primavera y otoño. Esto ha de suponer cambios en las políticas de promoción de destinos, adaptación a nuevas realidades de vacaciones laborales o acciones en cuanto a la captación de nuevos mercados.

El proyecto Espon-Climate $(2007-13)^{4}$ ha dibujado una serie de escenarios posibles de vulnerabilidad del territorio europeo ante el cambio climático; todo ello, teniendo en cuenta que cualquier evaluación de la vulnerabilidad se enfrenta a la incertidumbre de los modelos de cambio climático, del escenario de emisiones y de las tendencias futuras en el desarrollo socioeconómico (Figura 1).

En los últimos años se han desarrollado políticas de reducción de los efectos del cambio climático en los espacios y la actividad turística, por parte de las diferentes administraciones en los países desarrollados. La adaptación al cambio climático en la escala local resulta de especial interés por la inmediatez de las acciones y la participación de actores sociales directamente implicados en la gestión de políticas turísticas o de empresas. La Unión Europea aprobó en 2013 una Estrategia de Adaptación al cambio climático, que a través de ocho acciones persigue convertir a los países europeos en territorios más resilientes ante los cambios previstos en las condiciones climáticas. Para desarrollar estas acciones se han establecido tres prioridades a desarrollar en los años inmediatos: implementar las actuaciones previstas en los Estados miembros; mejorar la información sobre el cambio climático para poder tomar decisiones fundadas; y, actuar de forma prioritaria sobre sectores especialmente vulnerables. La plataforma Climate-Adapt reúne, en este contexto, la

4 Los resultados del proyecto Espon-Climate pueden consultarse en:

http://www.espon.eu/main/Menu_Projects/Menu_AppliedResearch/climate.html 
información sobre los proyectos europeos de adaptación al cambio climático que se están desarrollando en diferentes países en los últimos años.

Figura 1. Impactos del cambio climático en Europa.

Aggregate

potential impact

of climate change

highest negative

mediumnegative

low negative

no or marginal

low positive

no data
Regional leve: NUTS3 (2006) Source: ESPON Cimate, 2011 Origin ofdata: IRPUD, 2011 (2) UMS RIATE for administrative boundaries

This map does not necessarily refect the opinion of the ESPON Monitoring Committee
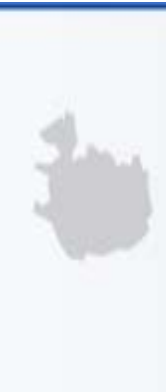
Uno de los espacios europeos que ha desarrollado actuaciones de adaptación ante el cambio climático de forma más efectiva en los últimos años es la región del Mar Báltico. Aquí se ha llevado a cabo el proyecto BaltCica (Climate Change in Baltic Sea Region). En este caso, la puesta en marcha de medidas ha tenido al municipio como escala principal de trabajo. Se han desarrollado fases de investigación con elaboración de informes y cartografía sobre los riesgos naturales relacionados con el cambio en las condiciones del clima (inundaciones, litoral), se han abordado medidas de adaptación, con fases de consulta pública y se han aprobado ordenanzas municipales para llevar a cabo las actuaciones programadas ${ }^{5}$. Filies y Schumacher (2013) han analizado el impacto del cambio climático para el turismo litoral de la región y señalan que la complejidad de adaptación de esta actividad que requiere medidas integradas en políticas globales de mitigación del problema (defensa estructural de la costa).

El análisis de estas políticas y prácticas en la escala local es el interés de nuestra investigación. Se realiza un repaso somero a las medidas que se han diseñado y puesto en marcha en los municipios turísticos españoles durante los últimos años. Se han destacado las actuaciones desarrolladas en áreas turísticas litorales que suponen ejemplos de buenas prácticas (Olcina, Sauri y Vera, 2014). A la vez que se ha centrado el análisis en el litoral mediterráneo dada su importancia como destino turístico en el conjunto del territorio español. En primera aproximación, el número mayor de acciones de reducción y adaptación ante el cambio climático se han relacionado con las mejoras en la gestión de la energía y agua, especialmente en áreas con escasez de estos recursos como el litoral mediterráneo español y el archipiélago canario (Hof y Blázquez, 2015; Gabardá, Rivas y Daunis, 2015; Rico, Sauri y Olcina, 2009). Y ello ha tenido un reflejo importante en las acciones que la propia empresa turística ha ido desarrollando en los últimos años que, en muchos casos, se ha convertido en pionera en la puesta en práctica de acciones de adaptación al cambio climático, como se analiza seguidamente.

\section{Impacto del cambio climático en Espña y sus efectos en las áreas turísticas litorales}

Hay tres procesos principales que pueden desarrollarse en España, por efecto del calentamiento global, con implicaciones directas en la actividad turística: a) un aumento de los extremos atmosféricos (mayor peligrosidad climática); b) una reducción de precipitaciones y de volúmenes de agua disponible; y c) la pérdida de confort climático en el sur y este peninsular por aumento térmico en los meses centrales de verano.

Algunos estudios han señalado una serie de efectos, a medio y largo plazo, en la actividad turística española a consecuencia del proceso planetario de calentamiento

\footnotetext{
Los resultados de este proyecto pueden consultarse en www.baltcica.org
} 
térmico que, en esencia, se resumen a (Bigano et al, 2008; Rosello, 2011; Bujosa y Rosello, 2011):

* Pérdida de cuota de mercado a nivel mundial, que pasará del $6 \%$ al 4,8\% en 2030.

* Reducción a largo plazo en el número de llegadas de turistas, estimada en un $20 \%$ para el año 2080 .

* Pérdida relativa de importancia del turismo de sol y playa como producto turístico debido a la falta de confort climático en verano.

* Posibles cambios en los destinos turísticos interiores, con pérdida de importancia del litoral mediterráneo como mercado turístico y aumento de la cuota de mercado en el litoral cantábrico, que se percibirá ya en 2030.

La modelización climática en latitudes medias y, específicamente en el ámbito mediterráneo, señala una serie de alteraciones para las próximas décadas que ponen en duda el cumplimiento de las exigencias climáticas en los destinos turísticos (Besancenot, 1991):

* El aumento de días sin lluvia que, en principio, aumentaría las posibilidades de disfrute se verá contrarrestado por la reducción de volúmenes de agua disponible que puede poner en peligro los abastecimientos de espacios turísticos.

* Temperaturas más altas en verano y calor húmedo, poco soportable, en zonas litorales. Pérdida, por tanto, de confort climático.

* Incremento de extremos atmosféricos; por tanto, nivel de riesgo mayor.

Como señala el $5^{\circ}$ Informe del IPCC (2014) hay una serie de manifestaciones en la atmósfera terrestre, cuya comprobación a partir del registro instrumental es cada vez más difícil. Se ha registrado un incremento de temperaturas en las tres últimas décadas que no encuentra explicación, sólo, por causas exclusivamente naturales (radiación solar). Hay otro factor que está alterando el funcionamiento "normal" del balance energético del planeta, al provocar un incremento del poder calorífico de la radiación de onda larga, originada en la superficie terrestre y marina que no sale a la atmósfera exterior porque queda confinada en los primeros kilómetros de la troposfera terrestre. Y este hecho está en relación con la presencia de gases primarios procedentes de la actividad económica humana $\left(\mathrm{CO}_{2}\right.$, oxido nitroso, metano) y depositados en la atmósfera o de la interacción de éstos con otros gases cuya contribución real al balance energético planetario sigue siendo una incertidumbre, como el ozono troposférico. En este sentido, una atmósfera que pierde su equilibrio térmico y se vuelve más cálida o más fría es una atmósfera que registra procesos de reajuste energético más violentos; esto es, los tipos de tiempo cambian con más rapidez e intensidad. Se hace más frecuente la génesis de situaciones de rango extraordinario. Esto es especialmente notable en las latitudes medias al ser el escenario de desarrollo de los movimientos de expansión de las masas de aire frías (de norte a sur) y cálidas (de sur a norte). Se estima, por tanto, que el cambio climático que pueda desarrollarse en las próximas décadas significará también en la 
variabilidad, de manera que el clima tiende a un calentamiento pero también a una mayor frecuencia en el registro de temperaturas extremas, con aumento de las medias máxima y mínima.

Por su parte, el informe sobre "Proyecciones climáticas para el siglo XXI" (Aemet, 2015), señala para el conjunto peninsular un incremento en las temperaturas máximas, en 2100 , entre $1^{\circ}$ y $7^{\circ} \mathrm{C}$ para diferentes escenarios de emisión de gases y de forzamiento radiativo $\left(\mathrm{w} / \mathrm{m}^{2}\right)$ en el Balance Energético Planetario hacia final de siglo (RCP4,5, RCP6,5 y RCP8,5); en las temperaturas mínimas el aumento se cifra entre $1^{\circ}$ y $6^{\circ}$ C. Por su parte, las precipitaciones se reducirían a finales del presente siglo, entre un 8 y $15 \%$ respecto a las medias del período 1961-1990, dentro de los márgenes de incertidumbre que reconoce el IPCC como necesarios en virtud de la incidencia que factores externos como el crecimiento demográfico, el desarrollo socioeconómico o el cambio tecnológico pueden tener en las emisiones de gases de efecto invernadero. Por lo común, oscilan entre el 5 y $10 \%$ para los diferentes escenarios.

A efectos de confort climático en áreas turísticas del litoral mediterráneo es significativo el aumento que se prevé en el número de días cálidos, de noches cálidas (noches tropicales y ecuatoriales) y en la duración de las olas de calor en todas las regiones del mediterráneo español. Se trata de variables que, unidas a valores de humedad atmosférica altos, se relacionan con la génesis de sensaciones térmicas de disconfort. La figura adjunta (Figura 2) refleja el destacado aumento de "noches tropicales" registrado en la ciudad de Alicante, a modo de ejemplo de lo ocurrido en otras localidades del litoral mediterráneo español. Se ha querido iniciar el período de representación de los datos en los años setenta del pasado siglo, período "frío" en la evolución de las temperaturas en todo el planeta, para destacar el brusco cambio que representan los valores de las décadas siguientes y el mantenimiento de la tendencia desde comienzos del presente siglo.

Figura 2. Incremento de noches tropicales $\left(>20^{\circ} \mathrm{C}\right)$ en Alicante, 1970-2015.

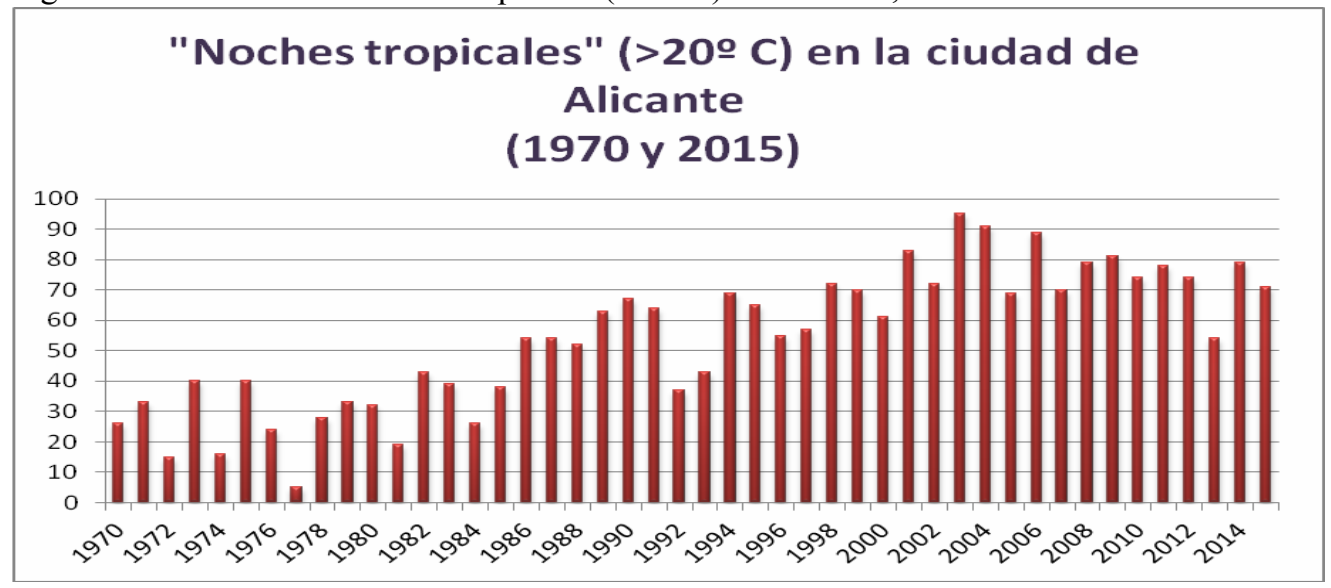

Fuente: AEMET (España). Elaboración propia. 
Y a ello hay que sumar el calentamiento de las aguas del Mediterráneo occidental en los meses cálidos del año que ha experimentado un aumentos en los últimos años prolongando, asimismo, el período de temperaturas elevadas $\left(<25^{\circ} \mathrm{C}\right)$ entre junio y septiembre. Para el conjunto de la cuenca del Mediterráneo, se ha estimado un incremento absoluto de $0.22^{\circ} \mathrm{C}$ por década, desde 1973 a 2008 (Skliris et al.2012). Por su parte, Miro Pérez (2014) a partir del uso de datos de satélite pertenecientes a la base de datos de la NOAA/NASA AVHRR Oceans Pathfinder, ha calculado el incremento térmico en las aguas del litoral próximo a la Comunidad Valenciana, para el período 1985-2007, estimando una pendiente anual por década de $0,26^{\circ} \mathrm{C}$ de incremento.

En estrecha relación con el comportamiento térmico del agua del mar está el efecto del calentamiento en la subida del nivel de mar y su afección a las áreas litorales. Desde 2002, el grupo de Ingeniería Oceanográfica y de Costas de la Universidad de Cantabria se desarrolla el proyecto C3E (Impacto del cambio climático en la costa española $\left.{ }^{6}\right)$. Como indican los resultados de este proyecto el aumento del nivel del nivel medio del mar en la zona Atlántico-Cantábrica sigue la tendencia media global observada entre 1,5 y $1,9 \mathrm{~mm} / \mathrm{año}$ entre 1900 y 2010 y de entre $2,8 \mathrm{~mm} /$ año y $3,6 \mathrm{~mm} /$ año entre 1993 y 2010. Sin embargo, existe una mayor incertidumbre en cuanto al nivel medio del mar en el Mediterráneo por efectos regionales. Por su parte, considerando un escenario tendencial de aumento de nivel del mar a 2040 (aproximadamente $6 \mathrm{~cm}$ ), las playas de la cornisa cantábrico-atlántica y norte de las Canarias experimentarán retrocesos medios cercanos a los 3 metros, 2 metros en el Golfo de Cádiz y valores medios entre 1 y 2 metros en el resto de las fachadas.

Un factor que, sin duda, va a influir en el grado de riesgo de la costa española frente al cambio climático es la ocupación humana del litoral, que ha experimentado un crecimiento importante en las dos últimas décadas. Como han señalado Ruiz Urrestarazu y Galdós (2013) lo más destacable de los datos que proporciona el proyecto Corine Land Cover es la formidable dinámica expansiva de las superficies artificiales en España que, entre 1987 y 2006, han experimentado un crecimiento de 347.471 ha, cifra que supone un incremento relativo del $51,9 \%$; proceso que se ha acelerado entre 2000 y 2006, con el dato sorprendente de transformación de 63 ha. al día de nueva superficie "artificializada", frente a las 31 ha. del intervalo 1987-2000. Los incrementos citados se deben en gran medida a la propagación de la superficie denominada tejido urbano discontinuo. Dicho aumento superficial coincide con años de una desaforada actividad urbanística que se traduce en un crecimiento espectacular de la construcción de viviendas y en la ocupación de suelo rústico ya que la urbanización extensiva adquiere un predominio destacado. Como indica Burriel de

6 Este proyecto integra 3 fases: Fase I, Evolución de cambios en la dinámica costera española; Fase II, Evaluación de efectos en la costa española; y Fase III, Estrategias frente al cambio climático en la costa. (Vid. Ministerio de Medio Ambiente, 2014). 
Orueta (2008), entre 1997 y 2006 el número de viviendas iniciadas en España fue de 5.636.231, casi el doble que en la década anterior. Esa cifra representa una ratio anual media de 13,3 viviendas por 1.000 habitantes, con el dato significativo de que en 1997 se inició la construcción de 324.599 viviendas, que se duplicaron en 2006 (760.170).

Esto ha traído consigo cambios importantes en los usos del suelo, produciéndose un crecimiento urbanístico descontrolado en muchas áreas de la costa española, especialmente en el litoral mediterráneo, que ha culminado con una "artificialización" rotunda de este espacio geográfico.

A efectos de valorar la subida del nivel del mar en la costa española, se ha desarrollado, junto al proyecto $\mathrm{C} 3 \mathrm{E}$, otros estudios que han aportado tasas diversas de incremento del nivel del mar, para los últimos veinticinco años, tal y como se recoge en la tabla adjunta (Tabla 1).

Tabla 1. Tasas de la subida del nivel del mar en la costa española, desde 1990, según diversos estudios.

\begin{tabular}{|l|l|c|}
\hline \multicolumn{1}{|c|}{ Estudio o Informe } & \multicolumn{1}{c|}{$\begin{array}{c}\text { Litoral cantábrico y } \\
\text { atlántico }\end{array}$} & Litoral mediterráneo \\
\hline Marcos et al. (2005) & $\begin{array}{l}\text { Entre }+2.12 \text { y }+2.91 \\
\text { mm/año }\end{array}$ & --- \\
\hline Marcos et al. (2009) & Entre 1.84 y $2.64 \mathrm{~mm} / \mathrm{año}$ & Entre $-0.6 \mathrm{y}+0.48 \mathrm{~mm} / \mathrm{año}$ \\
\hline $\begin{array}{l}\text { Instituto Español de } \\
\text { Oceanografía }\end{array}$ & --- & $\begin{array}{l}\text { Entre }+2 \mathrm{~mm} / \mathrm{año} \text { y }+10 \\
\mathrm{~mm} / \mathrm{año.}\end{array}$ \\
\hline Informe C3E (2014) & Entre 2.8 y 3.6 mm/año & \multicolumn{1}{c|}{ Sin determinar } \\
\hline
\end{tabular}

Fuente: Ministerio Medio Ambiente (2014) Cambio climático en la costa española.

El informe $\mathrm{C} 3 \mathrm{E}$ realiza, por último, una valoración económica de las pérdidas que se podrían generar en la costa española como efecto de la subida del nivel del mar, perdida de las playas e incremento de la cota de inundación en el litoral y llega a la conclusión siguiente: "Si la sociedad actual se viera enfrentada a la subida del nivel del mar considerada para el año 2100 , sin incorporar medidas de adaptación, el valor acumulado de las pérdidas futuras alcanzaría cifras entre 500 y 4.000 millones de euros, lo que supone cifras de entre el $0,5 \%$ y el $3 \%$ del PIB anual según las provincias y los escenarios"(Ministerio de Medio Ambiente, 2014).

\section{Experiencias de adaptación al cambio climático en municipios turísticos del litoral mediterráneo español}

Los planes oficiales que incorporan acciones de adaptación al cambio climático en materia turística, en España y en sus Comunidades Autónomas, son el Plan Nacional de Adaptación al Cambio Climático, los Planes estatales para el sector turístico, planes sectoriales como el de eficiencia energética, planes autonómicos de adaptación al cambio climático y los planes y programas autonómicos de política turística. Y a 
ello se suman las acciones que, desde el ámbito privado, han llevado a cabo las empresas turísticas en los últimos años, dentro de sus políticas de mitigación y adaptación a los efectos del cambio climático.

El Gobierno español, siguiendo el ejemplo del resto de países europeos, puso en marcha, en 2006, el Plan Nacional de Adaptación al Cambio Climático (PNACC), a propuesta de Oficina Española de Cambio Climático y de la Secretaría General para la prevención de la contaminación y del Cambio Climático del Ministerio de Medio Ambiente, con los siguientes objetivos:

* desarrollar los escenarios climáticos regionales para la geografía española.

* desarrollar y aplicar métodos y herramientas para evaluar los impactos, vulnerabilidad y adaptación al cambio climático en diferentes sectores socioeconómicos y sistemas ecológicos en España.

* aportar al esquema español de $\mathrm{I}+\mathrm{D}+\mathrm{i}$ las necesidades más relevantes en materia de evaluación de impactos del cambio climático.

* realizar un proceso continuo de actividades de información y comunicación de los proyectos Plan Nacional de Adaptación al Cambio Climático.

* promover la participación entre todos los agentes implicados en los distintos sectores y sistemas, con objeto de integrar en las políticas sectoriales la adaptación al cambio climático.

* elaborar informes específicos con los resultados de las evaluaciones y proyectos.

* elaborar informes periódicos de seguimiento y evaluación de los proyectos y del conjunto del Plan Nacional de Adaptación.

Para el diseño de políticas y medidas de actuación este Plan se basó en los resultados del informe sobre "Evaluación preliminar del Cambio Climático en España", elaborado en los primeros años del nuevo siglo y editado en 2005 por el Ministerio de Medio Ambiente. Sorprendentemente este Informe no ha merecido actualización en años posteriores. Eso si, la Oficina Española de Cambio Climático y la Agencia Estatal de Meteorología, como se ha señalado (vid. supra) ha ido actualizando las proyecciones climáticas para España en los últimos años; y, asimismo, el proyecto proyecto $\mathrm{C} 3 \mathrm{E}$ (Impacto del cambio climático en la costa española) ha ido ofreciendo resultados, -texto y cartografía- de la modelización realizada (vid. supra). Sería, sin embargo, necesaria una actualización regular de los diferentes apartados que se incluían en el citado informe, al estilo de lo que se lleva a cabo en algunas Comunidades Autónomas, como Cataluña o el País Vasco.

Con arreglo a estas pautas, el Plan Nacional de Adaptación al Cambio Climático ha incluido las siguientes medidas y acciones en materia turística:

* Evaluación del papel del clima actual en el sistema turístico español y los impactos que supondría el cambio climático por zonas y productos más vulnerables, integrando las diferentes escalas de manifestación del fenómeno. 
* Cartografía de zonas críticas y vulnerables para el turismo, bajo distintos escenarios de cambio climático.

* Desarrollo de sistemas de indicadores sobre la relación cambio climáticoturismo para su medición y detección.

* Desarrollo de modelos de gestión para optimizar las principales opciones adaptativas y las implicaciones en las políticas turísticas.

* Evaluación de los potenciales impactos del cambio climático en el patrimonio cultural (tangible e intangible) y su repercusión en el turismo

Estas acciones en materia turística es uno de los aspectos menos desarrollados del Plan Nacional de Adaptación al Cambio Climático En el Tercer Informe de Seguimiento del PNACC (2014) se señala que tan sólo se ha completado un estudio sobre el impacto del cambio climático en el turismo interior español, pero ni se ha elaborado un análisis de dicho impacto en el turismo de sol y playa, el de mayor importancia económica y social en nuestro país, ni tampoco del impacto en el turismo de nieve, actividad de importancia creciente en los últimos años, si, asimismo, se ha llevado a cabo una valoración integral del impacto del cambio climático en el sector turístico que debería servir como punto de partida para el desarrollo de programas y acciones concretas de adaptación en los próximos años.

Para impulsar las medidas de lucha contra el cambio climático, dentro de un programa general de mejora del medio ambiente (Planes PIMA de Impulso al Medio Ambiente) desarrollado entre 2014 y 2015, el gobierno ha aprobado un plan específico para la adaptación al cambio climático, el Plan PIMA-Adapta, que integra un conjunto de medidas concretas, de tipo estructural, a desarrollar en la costa española, en el dominio hidráulico y en los parques nacionales. En total son 46 actuaciones, con un presupuesto de 12 millones de $€$, que supone un cambio en la actitud del gobierno conservador de España que hasta este momento había minusvalorado las acciones contra el cambio climático, rompiendo una estrategia de actuación en esta cuestión desarrollada desde 2004. En síntesis es un programa tímido de medidas que contempla actuaciones de regeneración de playas, estabilización de taludes y dunas, aportación de arenas, restauración hidrológico-forestal, obras menores de defensa de avenidas y monitorización de cambio de especies de vegetación en parques nacionales. Tal vez, el mayor interés de este plan radica en la asignación de presupuesto para estudios de evolución de la línea de costa y de evaluación de riesgos asociados al cambio climático a escala provincial. En definitiva se trata de un plan muy modesto si se compara con las iniciativas que se están llevando a cabo en el contexto europeo.

En relación con el desarrollo de medidas de eficiencia energética en el sector turístico, España puso en marcha, hasta 2012, el Plan-E, con una aplicación especial en la actividad turística (Futur-E Turismo, 2009 a 2011), donde se contemplaban una serie de ayudas económicas para la mejora de la eficiencia energética de las 
instalaciones turísticas, el ahorro de energía y de agua y la implantación de nuevas tecnologías y sistemas de calidad, entre otros aspectos. En el último informe aprobado por la Secretaria de Estado de Cambio Climático, en julio de $2011^{7}$, se señalaba que "con la puesta en marcha de los planes Futures y Renove (un programa para revitalizar las instalaciones turísticas) se ha puesto a disposición del sector en dos años 1.900 millones de euros con los que se han financiado 6.830 proyectos en las diecisiete Comunidades Autónomas, generando una inversión inducida de 3.600 millones de euros".

En materia de política turística estatal, el principal instrumento es el Plan Nacional e Integral de Turismo, 2012-2015 (Instituto de Turismo de España, 2012). Este plan contiene referencias a la sostenibilidad de la actividad y a las acciones para llevarla a cabo, en colaboración con otras administraciones, para que pueda aplicarse en los destinos y recursos turísticos. En este sentido, las actuaciones que se han llevado a cabo desde la administración pública y desde el propio ámbito empresarial del sector turístico, han hecho énfasis sobre todo en la eficiencia energética. Más allá de este aspecto, ni en los programas ni en las medidas a aplicar hay acciones o líneas concretas relativas al cambio climático y a sus posibles efectos en este sector.

Por su parte, las Comunidades Autónomas han desarrollado también Planes y Estrategias de Adaptación al Cambio Climático, en los que la cuestión energética (reducción de emisiones, energías alternativas) ocupa la porción principal de las acciones programadas. En el ámbito del litoral mediterráneo, todas sus Comunidades Autónomas han desarrollado este tipo de estrategias, que en algún caso (Cataluña) se acompaña de la elaboración periódica de un completo informe sobre el estado del cambio climático y su modelización futura en el territorio de referencia. Para la adaptación de la actividad turística hay previstas una serie de actuaciones en cada región, que se vinculan a la promoción de destinos sostenibles, la incentivación de medidas de ahorro (energía, agua) en establecimientos hoteleros, las acciones de formación del personal y de información a los clientes de las instalaciones turísticas en las cuestiones de sostenibilidad. En general, se trata de acciones que persiguen la diversificación del producto turístico y la apuesta por la sostenibilidad como principio de actuación en la búsqueda de la calidad de los destinos, más que de medidas concretas de adaptación al cambio climático.

Frente a los planes y políticas desarrolladas por las Comunidades Autónomas españolas, líderes en materia turística, que están en una fase incipiente y de imposible evaluación de sus resultados, más interés han tenido las acciones locales de adaptación al cambio climático y sus riesgos (extremos atmosféricos) vinculados, llevadas a cabo en España en los últimos años se han desarrollado bien por propia iniciativa de los gobiernos municipales, en muy pocos casos, o bien en el marco de la

La Secretaría de Estado de Cambio Climático dejó de funcionar en noviembre de 2011, tras la victoria del Partido Popular en las elecciones generales celebradas en España. 
Red de Ciudades por el Clima, creada en 2005, y auspiciada por el Ministerio de Medio Ambiente y la Federación Española de Municipios y Provincias.

En 2011, el Ministerio de Medio Ambiente aprobó la Estrategia Española de Sostebilidad Urbana y Local, como adaptación al territorio español de la Estrategia Temática Europea de Medio Ambiente Urbano de 2006 (ETEMAU). El documento contiene una hoja de ruta de enorme interés para su aplicación en los municipios y ello debe suponer la puesta en marcha en los entes locales de una serie de planes sectoriales y de aprobación de ordenanzas relacionadas directamente con la sostenibilidad fundamentalmente ambiental de estos territorios. Asimismo, y con la referencia de la Ley del Suelo aprobada en 2008, se pretende dar un impulso a la integración de acciones de sostenibilidad ambiental en los planes de ordenación urbana. En la Estrategia se dedica un amplio apartado a las medidas de mitigación y adaptación del cambio climático que comprenden acciones relacionadas con la reducción de emisiones, energías limpias, residuos, modelo urbano, agua y movilidad sostenible.

La Federación Española de Municipios y Provincias, por su parte, ha desarrollado, en los últimos, años diferentes iniciativas para fomentar la acción local en materia de lucha y adaptación al cambio climático. A la creación de la mencionada Red de Ciudades Españolas por el Clima, ha seguido la elaboración desde 2009 de informes anuales de "Políticas Locales de lucha contra el Cambio Climático", la preparación de un documento informativo sobre "Vulnerabilidad al Cambio Climático a escala local" $(2010)^{8}$ y la redacción de una "Guía para el desarrollo de normativa local en la lucha contra el cambio climático" $(2012)^{9}$, con pautas para la redacción y puesta en marcha de ordenanzas municipales en los sectores relacionados con la mitigación y adaptación al cambio climático (energía, transporte, residuos, agua, vivienda, planeamiento urbano, participación, fiscalidad).

Desde 2006, y con una periodicidad bianual, esta Federación organiza una convocatoria para premiar las buenas prácticas en materia de adaptación al cambio climático. Esta convocatoria organiza los proyectos en diversos apartados (energía, movilidad, eco-innovación, educación y planificación territorial). En general, de la relación total de propuestas seleccionadas y de proyectos premiados en las cinco convocatorias desarrolladas se puede observar que las acciones dedicadas a cuestiones energéticas, tanto en edificios (instalación de energía solar) como en movilidad urbana (vehículos híbridos, bicicletas), y las orientadas a la sostenibilidad ambiental, en términos generales (mejora en el servicio de tratamiento de residuos sólidos urbanos, campañas de sensibilización), son las que más se han desarrollado,

8 Federación Española de Municipios y Provincias (2010) Vulnerabilidad al cambio climático a escala local. Ministerio de Medio Ambiente y Red Española de Ciudades por el Clima, Madrid, 310 p.

9 Federación Española de Municipios y Provincias (2012) Guía para el desarrollo de normativa local en la lucha contra el cambio climático, Ministerio de Medio Ambiente y Red Española de Ciudades por el Clima, Madrid, $253 \mathrm{p}$. 
frente a los proyectos relacionados con la ordenación territorial, que han tenido una consideración menor.

Ciudades turísticas del litoral mediterráneo español como Barcelona, Calvià, Marbella han aprobado Planes o Estrategias locales de adaptación al cambio climático y mejora de la resiliencia urbana ante este proceso. Pero sorprende que no son muchos, todavía, los ejemplos que pueden encontrarse en los municipios turísticos de esta parte del territorio español (Figura 3).

Figura 3. Secuencia de actuación de municipios españoles para la puesta en marcha de medidas de adaptación al cambio climático.

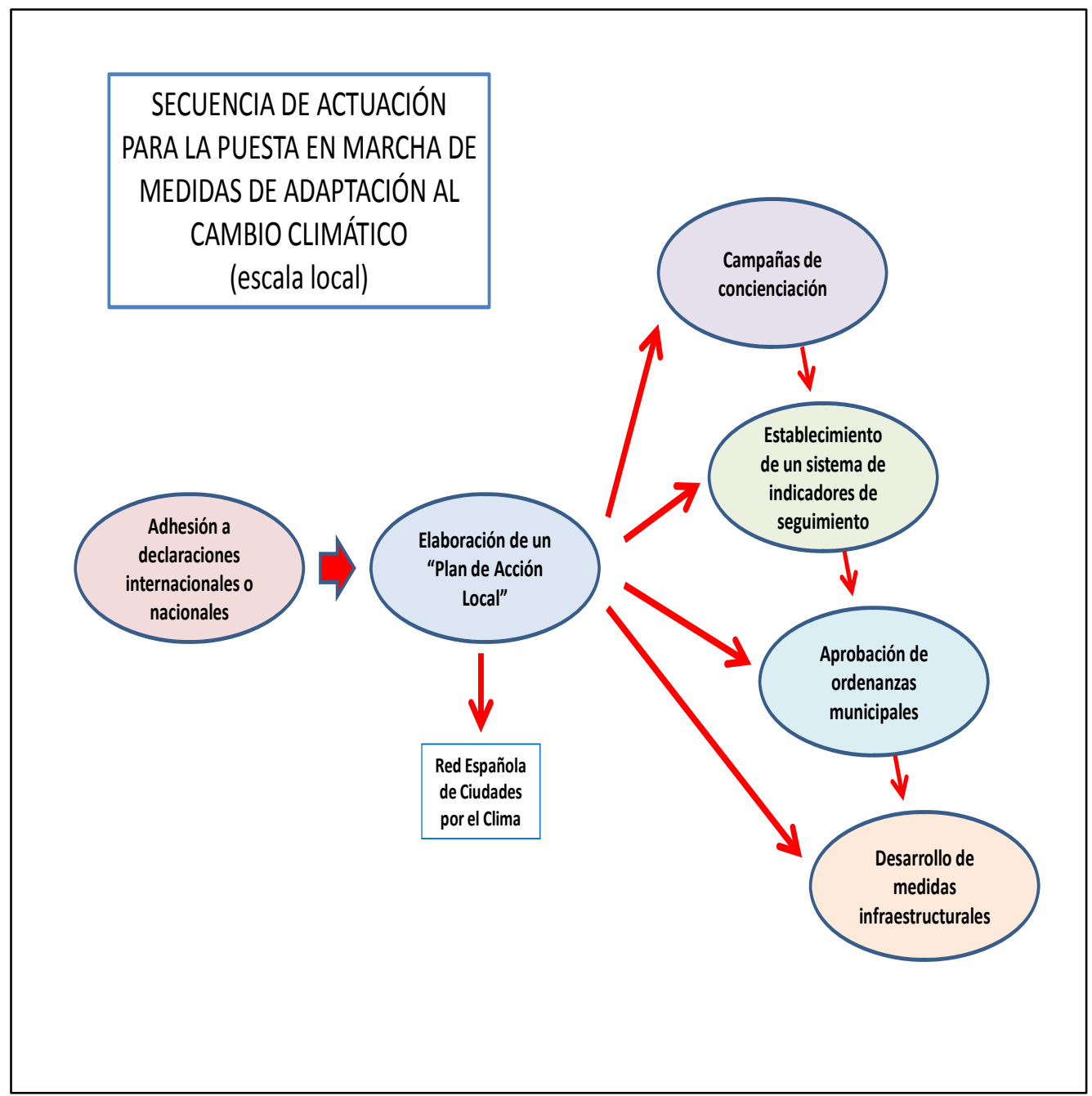

Fuente: Elaboración propia. 
Contrasta esta situación con el impulso que ha merecido esta cuestión, por contra, en el País Vasco, donde numerosos municipios han elaborados planes específicos de acción, ordenenanzas municipales y han desarrollado ya medidas concretas en los últimos años (p.e. Bilbao, Balmaseda, Hondarribia, Areatza, Tolosa, Durango, Amurrio, etc.). El propio Gobierno Vasco ha desarollado un manual de planeamiento urbanístico (2012) donde insta a los municipios a aplicar medidas de acción y adaptación ante el cambio climático.

En relación con actuaciones destacadas llevadas a cabo en los últimos años en áreas turísticas, sobresale el proyecto de autoabastecimiento energético, a partir de energía renovable, desarrollado en la Isla del Hierro, que supone un hito entre los proyectos de adaptación al cambio climático, de finalidad energética en un territorio turístico, llevados a cabo en los últimos años en España. En efecto, el proyecto " $100 \%$ Energías renovables para el Hierro", puesto en marcha en 2009, ha supuesto la construcción de un sistema hidroeólico capaz de cubrir el $100 \%$ de la demanda eléctrica de la isla, convirtiéndose ésta en la primera del mundo en autoabastecerse exclusivamente con electricidad renovable. El sistema de la central hidroeólica Gorona del viento está compuesto por dos depósitos de agua: uno inferior con capacidad para 225.000 metros cúbicos y otro depósito superior, aprovechando una caldera volcánica natural, con una capacidad para 500.000 metros cúbicos; un parque eólico de $10 \mathrm{MW}$; una central hidroeléctrica de $10 \mathrm{MW}$ con un salto neto de 682 metros; una central de bombeo; y una central de motores diesel ya existente la cual entraría en funcionamiento en casos de emergencia en los que no hubiera ni agua ni viento suficientes para cubrir la demanda (vid. figura). Con este proyecto se evitará el consumo anual de 6.000 toneladas de diesel, lo que equivale a 40.000 barriles de petróleo que tendrían que llegar importados y en barco a la isla, lo que supone un ahorro de más de 1,8 millones de euros anuales. Así mismo, se evitará la emisión a la atmósfera de 18.700 toneladas al año de $\mathrm{CO}_{2}$, principal causante del efecto invernadero.

En Barcelona, se ha establecido un eje estratégico de actuación en relación con el turismo que contempla la desestacionalización como "estrategia para adaptarse al cambio climático, ya que es posible que en las temporadas más calurosas la ciudad tenga que competir con otros destinos que puede conllevar pérdidas económicas importantes" ${ }^{10}$. El Plan integra medidas de una serie de planes sectoriales desarrollados en los últimos años en la ciudad en relación con cuestiones ambientales y de sostenibilidad.

Junto a estos programas y planes municipales de adaptación al cambio climático, Barcelona ha formado parte, entre 2010 y 2014, del proyecto "Prepared-Enabling Change", bajo financiación del septimo Programa Marco de la Comisión Europea. Este proyecto ha reunido a empresas de servicios públicos urbanos y centros de

\footnotetext{
${ }^{10}$ Vid. Plan de Resiliencia y Adaptación al Cambio Climático de Barcelona, 2014.

(Disponible en: http://ajuntament.barcelona.cat/ecologiaurbana/sites/default/files/BCN_resilient_def.pdf).
} 
investigación con el objeto de evaluar el grado de adaptación de 11 ciudades europeas (Arhus, Barcelona, Berlin, Eindhoven, Genova, Gliwice, Estambul, Lisboa, Lion, Simferopol) y la región de Gales en el Reino Unido, a los impactos del cambio climático en los temas de abastecimiento de agua y saneamiento. En su diagnóstico el proyecto ha establecido que, en relación con la fiabilidad del suministro de agua, la gestión actual no es lo suficientemente robusta frente al cambio climático; por su parte, en relación a los sistemas de alcantarillado de la ciudad, la morfología de la ciudad dificulta el transporte y descarga de agua de lluvia, provocando inundaciones en zonas cercanas a la costa como el barrio del Raval. Si además se considera el cambio climático, el aumento esperado de eventos de lluvia extrema y la subida del nivel del mar también añadirá más dificultades y riesgo de inundaciones ${ }^{11}$. A partir de estas conclusiones se han establecido 4 herramientas para su uso futuro en los programas de adaptación al cambio climático de los sistemas de abastecimiento y de alcantarillado del área metropolitana de Barcelona:

* sistema de ayuda a la decisión para la planificación de sistema urbanos de agua en regiones con estrés hídrico, basado en un enfoque multicriterio.

* esquema conceptual de captación y almacenamiento de agua en eventos extremos con elevados caudales, para promover el uso de recursos hídricos alternativos

* metodologías para la evaluación del riesgo de la escorrentía urbana

* nuevos métodos de trabajo para el control de sedimentos en la red de alcantarillado.

Se trata, en definitiva, de actuaciones que inciden en la adaptación en el ámbito urbano de un elemento del medio (agua) para el que los modelos de cambio climático señalan un comportamiento más extremo (inundaciones y sequías) en las próximas décadas en el área del litoral mediterráneo español.

Calviá aprobó en 2012 una Estrategia por el Clima (horizonte 2020) que contiene más de 140 proyectos que implican la reducción aproximada de 100 mil toneladas de $\mathrm{CO}_{2}$ a la atmósfera, además de diversos proyectos de participación, comunicación, sensibilización y difusión ciudadana en aspectos de sostenibilidad y cambio climático local.

Marbella ha incluido una serie de acciones de adaptación al cambio climático en el Plan Estratégico de la ciudad (Marbella 2022), que ha sido aprobado por el gobierno local en 2015. Entre dichas medidas destacan la elaboración de un Programa energético municipal para el desarrollo de energías alternativas y de un Programa de reducción del consumo energético municipal (alumbrado público, edificios e instalaciones públicas); el establecimiento de mecanismos de información a la población para el fomento del ahorro y la eficiencia energética, la puesta en marcha

11 Vid. información sobre el proyecto "Prepared-Enabling Change" en la web http://www.prepared-fp7.eu/ (Consultado en julio de 2015) 
de medidas de planificación y diseño de la edificación adaptadas al clima local y a los recursos renovables, que minimicen el gasto energético, así como de medidas de fomento de la rehabilitación energética de edificios existentes; $y$, por último, el fomento de plantas de cogeneración y/o trigeneración ${ }^{12}$.

Figura 4. Vista del "parque inundable" de la Playa de San Juan (Alicante) $)^{13}$.

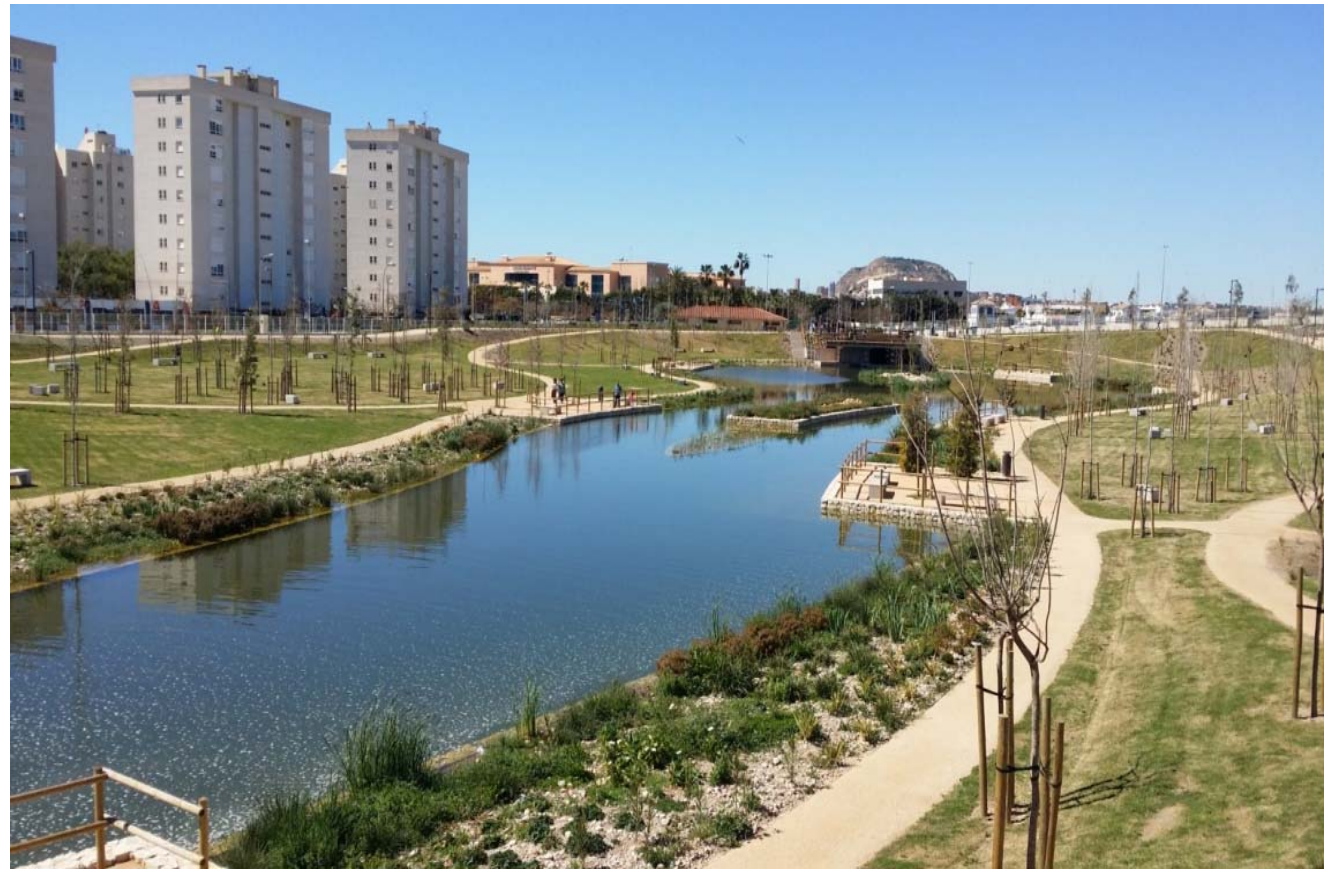

Fuente: Aguas Municipalizadas de Alicante (AMAEM).

El parque es, en suma, una actuación estructural "blanda" que tiene como finalidad convertirse en un depósito para almacenar temporalmente agua de lluvia y, al tiempo, ser un área recreativa con especies vegetales adaptadas al clima mediterráneo en diferentes ecosistemas (humedal y monte). Se trata de un proyecto, que sigue la traza de actuaciones similares llevadas a cabo en otras ciudades del mundo (p.e. parque La Aguada en Santiago de Chile).

12 Vid. Plan Estratégico Marbella-San Pedro, 2020. Disponible en: http://www.marbella.es/estrategia/docutecareferencias-bibliograficas/documentos-del-plan/documento-final.html

13 Ejemplo de adaptación a lluvias intensas más frecuentes esperables en un escenario de cambio climático. 


\section{Las acciones de adaptación al cambio climático en el ámbito empresarial turístico}

Es importante destacar las acciones que se están desarrollando desde hace años en la propia empresa turística y que afecta tanto tour-operadores como cadenas hoteleras, de diferente dimensión y a empresarios de la residencia turística de temporada (apartamentos). Desde los noventa del pasado siglo se han puesto en marcha acciones de adaptación al cambio climático que está dando resultados muy interesantes. Así, el mayor grupo de turoperación europeo (TUI), con más de 30 millones de clientes, desarrolla una política sólida de adaptación al cambio climático que se basa en la prevención y reducción de las emisiones y la adaptación de los diferentes sectores de actividad de la empresa con medidas de eficiencia hacia aspectos ambientales y específicamente relacionados con el cambio climático. Este operador turístico lleva a cabo una evaluación sistemática de su huella ambiental (energía, agua) a partir de la definición de indicadores, ha puesto en marcha un servicio técnico de seguimiento de políticas de protección del clima y ha aprobado un Código de Conducta que incluye el compromiso con la protección del clima como uno de sus principios principales, además de realizar campañas de sensibilización de esta tema entre clientes y socios. Estas cuestiones son de aplicación, como se ha mencionado, a sus diferentes sectores de actividad (transporte aéreo, hoteles, cruceros, vehículos de alquiler). Las acciones puestas en marcha por el tour-operador en la última década han sido reconocidas en 2011, por la organización "Carbon Disclosure Project"14.

En nuestro país, cabe mencionar las acciones desarrolladas en los últimos años desde Exceltur, la alianza para la excelencia turística, asociación formada por 25 de las más relevantes empresas de la cadena de valor turística. Esta organización, que ha sido pionera en afrontar nuevo retos para el sector empresarial turístico, cuenta entre sus estudios y publicaciones con Monitur (Exceltur, 2011), ranking de competitividad turística de las comunidades autónomas de España, que analiza la posición competitiva de las 17 comunidades, organizando los indicadores en pilares. Uno de esos pilares es la ordenación y condicionantes competitivos del espacio turístico. Un pilar que integra variables como son la protección del territorio, densidad urbanística de los destinos y compromiso ambiental y, a su vez, se desglosa mediante indicadores, tales como el tratamiento de residuos, reutilización de aguas, gestión ambiental de playas y adhesión a programas de compromiso ambiental.

Por su parte, grandes grupos hoteleros internacionalizados, como Meliá, $\mathrm{NH}$ o Riu, desarrollan sus propias políticas y acciones en materia de sostenibilidad, que se concretan en el marco de planes medioambientales, con el desarrollo de líneas para la reducción de consumo de energía y agua, emisiones de $\mathrm{CO} 2$, reducción de residuos,

14 Esta organización fue creada en 2000 y sus informes anuales se han convertido en una referencia importante para empresas e instituciones en materia de políticas y acciones de lucha contra el cambio climático. (Vid. https://www.cdp.net/en-US/Pages/HomePage.aspx). 
apuesta por energías renovables, entre otras actuaciones. Este tipo de acciones pueden entenderse en el marco de políticas generales posicionamiento de la compañía y de reducción de costes empresariales ya que, por ejemplo, es notable el efecto de la renovación de instalaciones eléctricas y de agua, con efectos evidentes de disminución de consumo por plaza hotelera y día en estas dos variables ambientales (Tabla 2). Aunque también responden a compromisos que tratan de estar en consonancia con las preocupaciones y sensibilidades ambientales que manifiesta la propia clientela. La misma definición que aporta Meliá Hotels International al respecto de su política de sostenibilidad es elocuente: "La sostenibilidad es un elemento inherente al posicionamiento como compañía, tanto presente como futuro, que se convierte en un eje vertebrador del modelo de negocio, asegurando así la creación de valor económico de forma sostenible para la compañía. Buscamos así potenciar un modelo de negocio sostenible, haciendo que nuestros grupos de interés nos elijan por ser una empresa hotelera responsable" ${ }^{\text {"15 }}$.

Por su parte, la cadena NH HOTEL GROUP dispone de un plan medioambiental, como plan estratégico, para el logro de sus fines en la materia y la organización de las acciones $^{16}$. Los objetivos del Plan Estratégico Medioambiental (o Plan 20-20-20-20) se concretan en la reducción de un $20 \%$ en los consumos de energía y agua, en la generación de residuos y en la reducción de la huella de carbono.

Tabla 2. Estrategias de reducción de agua y energía en grandes cadenas hoteleras (2013-2015)

\begin{tabular}{|c|c|c|}
\hline $\begin{array}{c}\text { CADENA } \\
\text { HOTELERA }\end{array}$ & AGUA & ENERGÍA \\
\hline Melia Group & $\begin{array}{c}\text { De } 500 \text { l/plaza/día (2013) } \\
\text { a } 460 \text { 1/plaza/día (2015) }\end{array}$ & $\begin{array}{c}\text { De } 22,30 \mathrm{Kw} / \text { plaza/noche }(2013) \text { a } \\
21,2 \mathrm{Kw} / \text { plaza/noche }(2015)\end{array}$ \\
\hline HN Hotels & $\begin{array}{c}\text { De } 303 \text { 1/plaza/día (2013) } \\
\text { a } 298 \text { 1/plaza/día (2015) }\end{array}$ & $\begin{array}{c}\text { De 55,52 Kw/habitación/noche } \\
\text { (2013) a 51,43 } \\
\text { Kw/habitación/noche (2015) }\end{array}$ \\
\hline
\end{tabular}

Fuente: Memorias anuales de responsabilidad corporativa de las cadenas hoteleras.

15 Vid. enlace http://www.meliahotelsinternational.com/es/sostenibilidad.

16 Vid. enlace http://corporate.nh-hoteles.es/es/responsabilidad-corporativa-y-sostenibilidad/gestion/medioambiente/plan-medioambiental-nh-hoteles 
Es importante reseñar las acciones que desarrollan estas grandes cadenas hoteleras para reducir su huella de carbono en los últimos años. Destaca, al respecto, el caso de NH que ha disminuido su huella de carbono en un $31 \%$ desde 2008 , merced a la puesta en marcha de un Plan de Eficacia Energética (2014-18) con inversiones de 31 millones de $€$. De este modo, $N H$ ha sido la primera cadena hotelera mundial en obtener la certificación ISO 50.001 por su apuesta por la eficacia energética. Del mismo modo que también es significativo el programa de actuaciones del grupo Meliá, en cuya web corporativa, dentro del apartado de sostenibilidad, aparece de forma explícita la cifra de huella de carbono emitida en 2015 y el porcentaje de reducción que supone respecto a la medición de 2011, un 6'3\% inferior ${ }^{17}$.

En general, la política medioambiental que desarrolla la gran empresa turística se concreta mediante acciones de gestión en diferentes áreas (emisiones de $\mathrm{CO} 2$, reducción de residuos, energías renovables, reducción del consumo de agua y de energía, protección de la biodiversidad) y en la consiguiente obtención de certificaciones, que pueden considerarse un indicador de compromiso por este tipo de acciones que adquiere la cadena hotelera o el empresario turístico particular. En el caso de Riu, cuenta con el distintivo denominado 'Travelife Gold Award', que certifica los hoteles que son medioambiental y socialmente responsables. Con estas certificaciones la cadena cuenta actualmente con más del $50 \%$ de sus hoteles certificados y da un paso más en su plan de responsabilidad social corporativa ${ }^{18}$. Travelife trabaja con listas de comprobación y estándares para verificar que un alojamiento cumple todos los criterios incluidos en la lista de comprobación. Esta lista se ajusta al tamaño del establecimiento y permite incluso llegar a un distintivo de excelencia ${ }^{19}$. En el caso del grupo Meliá, la gestión sobre criterios de sostenibilidad permite a la compañía contar con una importante herramienta de mejora continua de la actividad diaria de sus hoteles enfocada a la mitigación del impacto ejercido sobre el entorno. Esa gestión es avalada y certificada por una organización externa independiente, lo que dota de una mayor credibilidad y transparencia a esta apuesta. De este modo, para sistematizar, gestionar y evaluar los avances en las estrategias de

17 Vid. enlace http://www.meliahotelsinternational.com/es/sostenibilidad.

18 Vid. enlace http://www.riu.com/es/sostenibilidad/inicio.jsp.

19 Vid. enlace http://www.travelife.org/Hotels/landing_page.asp. Por otra parte, no deja de haber grandes paradojas ya que mientras las cadenas certifican sus establecimientos con distintivos ambientales, se presentan proyectos envueltos en polémicas, como el caso del hotel Riu Riviera Cancún, proyecto de 536 habitaciones y 95 millones de dólares, que la cadena española pretende construir en un terreno aledaño al Área Natural Protegida Manglares de Nichupté y sobre el cual el Centro Mexicano de Derecho Ambiental (Cemda) anunció que iniciará acciones para evitar que se apruebe la Manifestación de Impacto Ambiental, mientras que la Secretaría de Medio Ambiente y Recursos Naturales ya negó los permisos ambientales. El problema, según recoge la prensa (El Economista, 08/11/2015) es que el proyecto afecta a un área natural protegida y carece de estudio que justifique un proyecto que "contraviene a todas luces la Ley de Cambio Climático" en palabras de Alejandra Serrano Pavón, coordinadora del Cemda en Quintana Roo, por entender que hay un estudio elaborado por la Secretaría de Turismo que indica que la playa y toda la zona es vulnerable a los efectos del cambio climático (http://eleconomista.com.mx/estados/2015/11/08/ahora-quieren-frenar-hotel-riu). 
sostenibilidad, se trabaja con entidades avaladas o reconocidas por el GSTC (entidad de ámbito internacional dedicada a la promoción del Turismo Sostenible que aboga por un conjunto de principios universales - llamados Criterios Globales de Turismo Sostenible - concebidos para asegurar la gestión responsable de los destinos turísticos) como las certificaciones Earthcheck, Instituto de Turismo Responsable (ITRBiosphere), Travelife, ISO y Leed, principalmente. Recientemente, Meliá Hotels International se ha incorporado al Programa Ecolíderes/GreenLeaders de Tripadvisor que pone de relieve la apuesta por la sostenibilidad de los establecimientos en un entorno online de referencia.

La política de certificaciones en turismo sostenible se presenta, pues, como herramienta de mejora continua de los hoteles, en cuanto a su actividad diaria y al impacto ejercido sobre el entorno natural y/o sociocultural. La certificación ambiental hace referencia, por tanto, a una calidad ambiental que garantiza la correcta utilización de los recursos y además aporta al cliente seguridad sobre el máximo respeto medioambiental en el hotel. Asimismo, al ser certificados emitidos por una organización o entidad independiente, se otorga una mayor credibilidad y transparencia al compromiso y a las acciones que los establecimientos llevan a cabo. Para el logro de certificaciones y distintivos, se esencial la implantación de un sistema de gestión medioambiental en los hoteles.

Por su parte, las pequeñas empresas turísticas del litoral mediterráneo español, agrupadas en asociaciones empresariales, aunque no alcanzan a elaborar planes ambientales como los que se han comentado para el caso de las grandes cadenas, han puesto de relieve su compromiso ambiental (explicitado en algunos casos en su propia página web) y han desarrollado también en los últimos años actuaciones de adaptación, sobre todo referidas al fomento del ahorro de energía y de agua en apartamentos y hoteles. Así, por ejemplo, en Benidorm, destino emblemático del modelo turístico español, la asociación Hosbec, que aglutina a 234 empresas que suman casi 74.000 plazas de alojamiento turístico, asesora y apoya a sus asociados sobre normas de sistemas de gestión en calidad y medio ambiente. En el apartado ambiental, la Norma UNE EN-ISO 14001:2015 recoge los requisitos a cumplir para implantar un Sistema de Gestión Medioambiental, con el objetivo de la protección ambiental y la prevención de la contaminación en equilibrio con las necesidades socioeconómicas. Por su parte, el Reglamento EMAS (Sistema Comunitario de Ecogestión y Auditoria), define un modelo de Gestión que permite la Evaluación y Mejora del Comportamiento Medioambiental, y la difusión de la información al público en general y a los agentes interesados. Hosbec también ofrecen apoyo en la implantación de la Norma ISO 50001, Sistemas de gestión de la Energía, norma de reciente publicación, que permite disponer de un sistema integrado de gestión y planificación del consumo de energía, optimizando el consumo de recursos energéticos, y desarrollando una política de concienciación en el uso de las buenas prácticas en eficiencia energética. 
Figura 5. Medidas de adaptación al cambio climático desarrolladas por la empresa turística (hoteles y apartamentos).

\section{ACCIONES DE ADAPTACIÓN ANTE EL CAMBIO CLIMÁTICO DE LA EMPRESA TURÍSTICA}

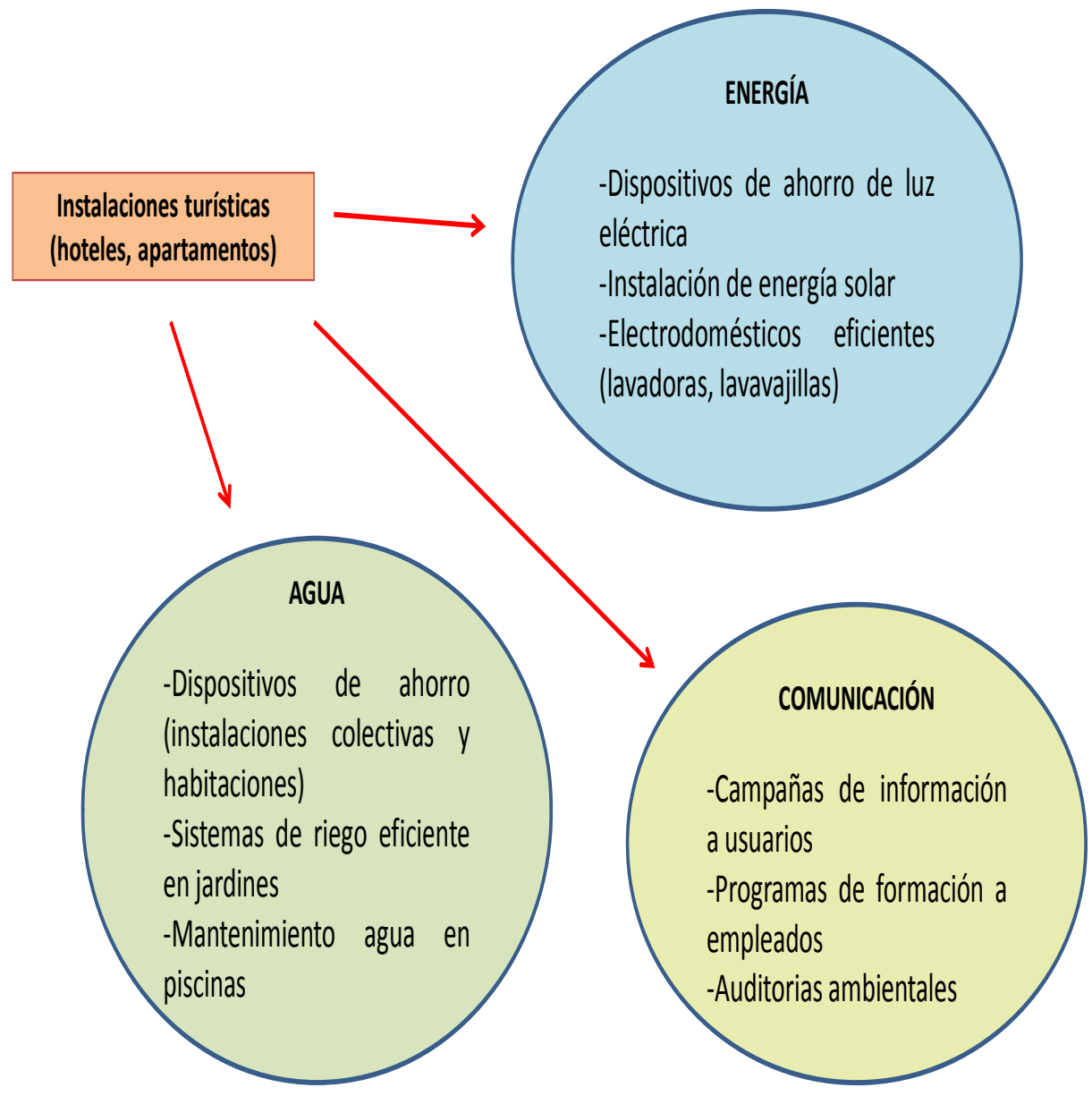

Fuente: Elaboración propia. 
En este sentido, hay que tener en cuenta el papel que han tenido las ayudas a empresas del sector puestas en marcha por las administraciones, estatal y autonómica, en los últimos años en relación con el fomento de medidas generales de sostenibilidad y, específicas, de ahorro de energía y agua. Así, una relación de medidas puesta en marcha por la planta hotelera de las áreas turísticas del litoral mediterráneo español, en los últimos quince años, contempla diferentes aspectos relacionados con la eficiencia energética, ahorro de agua y campañas de concienciación en el propio establecimiento turístico (Figura 5).

En bastantes casos, se han aprovechado procesos de renovación de la planta hotelera y la puesta en marcha de programas de ayudas estatales para llevar a cabo dicha renovación. Debe tenerse en cuenta que la implantación de medidas de reducción de consumo de agua y la estrecha relación que ello tiene con el gasto energético anual de un establecimiento hotelero, puede llegar a suponer una disminución del $25 \%$ en la factura energética de un hotel. Al mismo tiempo, para impulsar medidas de ahorro de agua y energía, los hoteles han desarrollado, en los últimos, campañas de sensibilización sobre ahorro y uso sostenible del agua, dirigidas tanto a clientes como a trabajadores.

Por último, una línea de actuación futura deberá ser la reutilización de aguas residuales en las propias instalaciones hoteleras. En la encuesta realizada en el presente estudio, se ha puesto de manifiesto la falta total de acciones de los hoteles dentro de esta estrategia de ahorro de agua. En el informe sobre usos del agua en el área metropolitana de Barcelona (Domene, Sauri et al. 2004) se señalaba la implantación de redes de aguas grises para inodoros en hoteles como una posible medida de ahorro de agua aplicar en este ámbito de estudio. A pesar de que se señalaban ahorros de agua del $10 \%$ respecto al consumo total anual de un hotel, los autores aconsejaban la necesidad de estudiar bien la viabilidad de la inversión a realizar en función del tamaño de la instalación hotelera. La reutilización del agua utilizada en lavabos y duchas de las habitaciones para los inodoros, a partir de la instalación de depósitos comunitarios para su tratamiento y posterior utilización en redes de aguas grises con destino a los inodoros supone, en efecto, una inversión costosa que debe valorarse a la hora de aplicar esta medida en un hotel. Otra posibilidad, de coste menor, es el aprovechamiento de agua de las duchas existentes en las piscinas de los hoteles para el rellenado diario que debe realizarse en las propias piscinas y que supondría inversiones asumibles en un hotel.

\section{Conclusiones}

Frente al escaso protagonismo que el cambio climático tiene en los planes y programas de escala estatal y regional, los municipios y las empresas turísticas han desarrollado una serie de iniciativas de gran interés y que comprenden acciones en diferentes ejes (energía, agua, movilidad, reducción riesgos, ordenación del territorio). La administración local, en áreas turísticas de sol y playa va siendo consciente de la importancia de una planificación a medio y largo plazo de los destinos en el marco de los principios de sostenibilidad ambiental y territorial. La gran empresa turística 
(touroperadores, cadenas hoteleras) ha ido incorporando mecanismos de gestión ambiental sostenible que se establecen, en la actualidad, como objetivos básicos en su responsabilidad social corporativa y en la cuenta anual de resultados. Y junto a ello, la obtención de certificaciones en turismo sostenible se presenta, en estos casos, como herramienta de mejora continua de los hoteles que garantiza la correcta utilización de los recursos y aporta seguridad al cliente sobre el máximo respeto medioambiental en el hotel. La pequeña empresa turística, por su parte, ha entendido que, en el marco de un mercado global, la apuesta por lo ambiental como marca de diferenciación es una exigencia creciente de la demanda y aporta beneficios en la explotación de los establecimientos (hoteles, apartamentos).

En las próximas décadas las líneas de actuación principales para la adaptación al cambio climático en la escala local en áreas turísticas del litoral mediterráneo español irán encaminadas a la potenciación de programas de mejora de la eficiencia energética en las viviendas turísticas (hoteles y apartamentos), al mantenimiento y potenciación de las actuaciones de ahorro de agua en municipios e instalaciones turísticas privadas, a la mejora del acondicionamiento térmico de las viviendas $\mathrm{y}$, en el plano de la gobernanza de los municipios, a la elaboración de planes de ordenación urbana que tengan en cuenta los aspectos del cambio climático y de los riesgos climáticos asociados.

Por contra a lo desarrollado en diversos países europeos, y contando con algunos ejemplos internacionales de buenas prácticas en este tema (Australia, Japón), España lleva varis años de retraso en la puesta en marcha de proyectos y medidas concretas de adaptación al cambio climático. Esta afirmación, válida para el conjunto de sectores económicos de nuestro país, cobra especial relevancia en la actividad turística debido a su valor estratégico como actividad generadora de fuertes ingresos y creación de empleo. El cambio climático puede verse como una oportunidad de incorporar, de forma progresiva, cambios en la trama territorial de los destinos, con vistas a su adaptación a los efectos del calentamiento global, y en la propia dinámica de las empresas turísticas, que debe comenzar a reflexionar sobre las transformaciones (demanda, estacionalidad) a que va a obligar el futuro escenario climático. La escala local se muestra especialmente idónea para desarrollar este tipo de actuaciones, pero debe contar con la implicación de los agentes implicados en la actividad turística y el desarrollo de políticas de incentivación, estatales y regionales, que favorezcan su implantación a medio plazo.

\section{Bibliografía}

AEMET (Agencia Estatal de Meteorología) (2015) Proyecciones Climáticas para el siglo XXI en España. Disponible en: http://www.aemet.es/es/serviciosclimaticos/cambio_climat [Consultado: enero 2016].

Amelung, B.; Nicholls, S.; Viner, D. (2007) "Implications of global climate change for tourist flows and seasonality", Journal of Travel Research, 45, 285-296.

Anton Clavé, S.; Rullan Salamanca, O.; Vera Rebollo, J.F. (2011) "Mass Tourism Development on the Mediterranean Coast", Tourism Geographies, 13:3, 495-501. 
Baños Castiñeira, C.J.; Vera Rebollo, J.F.; Díez Santo, D. (2010) "El abastecimiento de agua en los espacios y destinos turísticos de Alicante y Murcia", Investigaciones Geográficas, $\mathrm{n}^{\mathrm{o}} 51,81-105$.

Barton, J.R. (2009) “Adaptación al cambio climático en la planificación de ciudades-regiones”, Revista de Geografía Norte Grande, 43, 5-30.

Besancenot, J. P. (1991) Clima y Turismo. Ed. Masson, Barcelona, 224 p.

Biesbroek, R.G., Swart, R. J., Carter, T. R., Cowan, C., Henrichs, Th., Mela, H., Morecroft, M.D. and Rey, D. (2010) "Europe adapts to climate change: Comparing National Adaptation Strategies", Global Environmental Change, 20, 440-450.

Bigano, A. Hamilton, J.M. And Richard, S.J.Tol (2008) "Climate change and tourism in the Mediterranean", Working Paper FNU-157. Research Unit Sustainable and Global Change. Hamburg University. Disponible en http://www.fnu.zmaw.de/HTM.5681.0.html.

Bujosa, A. y Rosello, J. (2011) "Cambio climático y estacionalidad turística en España: un análisis del turismo doméstico de costa”, Estudios de Economía Aplicada, vol. 29-3, 863880.

Ceron, J. P. and Dubois, G. (2005). "Limits to tourism? A backcasting scenario for a sustainable tourism mobility in 2050". Symposium "The end of Tourism? Mobility and Local-global connections", Eastbourne, CTPS.

Cunillera, J., Mas, J., Manzano, A., Prat N., Munne, A., Sauri D. (eds.) (2009) Aigua i Canvi Climàtic. Barcelona: Agència Catalana de l'Aigua.

Donges, L., Haller, I. and Schernewski, G. (2013) "Tourists'perception of coastal changes. A contribution to the assessment of regional adaptation strategies?" in Schmidt-Thomé. P. and Klein, J. (ed.) Climate Change Adaptation in practice. Wiley-Blackwell, Oxford, 239252.

Dubois G. and Ceron, J.P. (2006) "Tourism and climate change: Proposals for a research agenda", Journal of Sustainable Tourism, 14 (4), 399-415.

Espon Atlas EU 2020 (2013) Territorial Dimensions of the Europe 2020 Strategy. European Union. Luxembourg, $66 \mathrm{p}$.

Espon Climate. (2011) Climate Change and Territorial Effects on Regions and Local Economies. Main Report. Available at: http://www.espon.eu/export/sites/default/Documents/Projects/AppliedResearch/CLIMATE /ESPON_Climate_Final_Report-Part_B-MainReport.pdf.

European Comission (2014) Climate Change report. Special Eurobarometer 409, march. Directorate-General for Communication (DG COMM "Strategy, Corporate Communication Actions and Eurobarometer" Unit. . Available on: http://ec.europa.eu/public_opinion/archives/ebs/ebs_409_en.pdf

Exceltur (2011): MoniTUR 2010. Monitor de competitividad turística relativa de las comunidades autónomas españolas. Exceltur y Deloitte, 75 pp. Available on: http://exceltur.org/wp-content/uploads/2014/10/MONITUR-2010_INFORME.pdf

Federación Española de Municipios y Provincias (2006) Cambio climático en las ciudades costeras. Red Española de Ciudades por el Clima. Ministerio de Medio Ambiente, Madrid, $172 \mathrm{p}$. 
Federación Española de Municipios y Provincias (2007) Guía práctica para la aplicación de la Estrategia Local de Cambio Climático. Red Española de Ciudades por el Clima. Ministerio de Medio Ambiente, Madrid, 670 p.

Federación Española de Municipios y Provincias (2009) Metodología para el cálculo del Sistema de Indicadores de Diagnóstico y Seguimiento del Cambio Climático. Red Española de Ciudades por el Clima. Ministerio de Medio Ambiente, Bilbao, 61 p.

Filies, Ch. y Schumacher, S. (2013) "Climate change impacts on Baltic coastal tourism and the complexity of sectorial adaptation" in Schmidt-Thomé. P. and Klein, J. (ed.) Climate Change Adaptation in practice. Wiley-Blackwell, Oxford, 225-238.

Gabarda Mallorquí, A., Ribas Palom, A. y Daunis I Estadella, J. (2015) "Desarrollo turístico y gestión eficiente del agua. Una oportunidad para el turismo sostenible en la Costa Brava (Girona)", Investigaciones Turísticas n 9, Universidad de Alicante, 50-69.

Gossling, S., P. Peeters, et al. (2012). "Tourism and water use: Supply, demand and security. An international review." Tourism management(33), 1-15.

Gössling, S., Peeters, P. and Scott, D. (2008) "Consequences of Climate Policy for International Tourist Arrivals in Developing Countries”. Third World Quarterly 29(5), 873-901.

Hall, C.M. and J. Higham (eds.) (2005) Tourism, recreation and climate change: International perspectives. Clevedon UK: Channel View Publications.

Hein, M., Metzger, J. and Moreno, A. (2009) "Potential impacts of climate change on tourism; a case study for Spain", Current Opinion in Environmental Sustainability $\mathrm{n}^{\mathbf{0}} 1$, , Elsevier, pp. 170-178. Disponible en: http://wordpress.reilumatkailu.fi/wpcontent/uploads/2012/03/artikkeli3.pdf.

Hof, A. y Blázquez-Salom, M. (2015) "Changing tourism patterns, capital accumulation, and urban water consumption in Mallorca, Spain: a sustainability fix?”, Journal of Sustainable Tourism, vol. 23, $\mathrm{n}^{\mathrm{o}} 5,770-796$

Hunt, A. and Watkiss, P. (2011) Climate change impacts and adaptation in cities: a review of the literature. Climatic Change, 104 (1), 13-49.

Instituto de Turismo De España (2012): Plan Nacional e Integral de Turismo 2012-2015. Ministerio de Industria, Energía y Turismo, Secretaría de Estado de Turismo, Turespaña, Madrid, $\quad 124 \quad$ pp. Disponible en: http://www.tourspain.es/eses/VDE/Documentos\%20Vision\%20Destino\%20Espaa/Plan\%20Nacional\%20e\%20Integr al\%20de\%20Turismo\%202012_2015_FINAL_REVISADO\%20150313.pdf

Intergovernmental Panel on Climate Change (IPCC) (2014). Climate change 2014: Synthesis report. En R. K. Pachauri \& L. A. Meyer (Eds.), Contribution of working groups I, II and III to the fifth assessment report of the intergovernmental panel on climate change. Geneva, Switzerland. Disponible en: http://www.ipcc.ch/report/ar5/syr/

Irigoy, I., Artigues, A.A., y Blazquez-Salom, M. (2013) "El papel de Estado en la renovación urbano-turística de espacios turísticos. El caso de la playa de Palma, Mallorca, España", Rev. Bitacora22, 1, Universidad Nacional de Colombia, 141-152.

Jarva, J., Nuottimäki, K., Kankaanpää, S., Tarvainen, P. (2014) Climate-Proof Living Environment. Methodologies, tools and practical recommendations for climate change adaptation in the Kymenlaakso and Uusimaa regions and the Helsinki Metropolitan Area. Geological Survey of Finland, Helsinki, 55 p. 
JCR (2014) Climate Impacts in Europe. The JRC PESETA II. European Commission, Luxembourg, $155 \mathrm{p}$.

Junta de Andalucía (2013): Plan General de Turismo Sostenible de Andalucía [2014 - 2020], Consejería de Turismo y Comercio, Junta de Andalucía, 2 vols. Disponible en: http://www.turismonuevasideas.org/plang/documentos-general

Kazmierczak, A. y Carter, J. (2010) Adaptation to climate change using green and blue infrastructure. A database of case studies. Database prepared for the Interreg IVC Green and blue space adaptation for urban areas and eco towns (GRaBS) project. University of Manchester., $\quad 182 \quad$ p. $\quad$ (Disponible $\quad$ en: http://www.grabseu.org/membersArea/files/Database_Final_no_hyperlinks.pdf). Consultado en: julio 2015 .

KPMG (2008) Climate changes your bussines. KPMG Global Sustainable Services, The Netherlands, $\quad 85 \quad$ p. $\quad$ Disponible en: http://www.kpmg.com/EU/en/Documents/Climate_Changes_Your_Business.pdf

López García, Mª. J. (1991) La temperatura del mar Balear a partir de imágenes de satélite. Universidad de Valencia, $158 \mathrm{pp}$.

March, H.; Sauri, D. and Olcina, J.(2014) "Rising Temperatures and Dwindling Water Supplies? Perception of Climate Change Among Residents of the Spanish Mediterranean Tourist Coastal Areas", Environmental Management no 53, 181-193.

Marcos M., G. Jordà, D. Gomis y B. Pérez, (2011) "Changes in storm surges in southern Europe from a regional model under climate change scenarios", Global and Planetary Change, 77, 116-128.

Marcos M., M.N. Tsimplis y Shaw, A.G.P. (2009) "Sea level extremes in southern Europe", Journal of Geophysical Research, 114, C01007.

Meira Cartea, P.A. (Dir.); Arto Blanco, M.; Heras Hernández, F.; Iglesias Da Cunha, L.; Lorenzo Castiñeiras, J.J. y Montero Souto, P. (2013) La respuesta de la sociedad española ante el cambio climático, Fundación Mapfre, Madrid, 223 p.

Meliá Hotels Group (2014) Informe Anual y RSC. Madrid, 68 p.

Miro Pérez, J.J. (2014) Downscaling estadístico de series climáticas mediante redes neuronales. Reconstrucción en alta resolución de la temperatura diaria para la Comunidad Valenciana. Interpolación espacial y análisis de tendencias (1948-2011). Tesis doctoral. Inédita. Universidad de Alicante, $523 \mathrm{p}$.

NH Hotel Group (2014) Informe Anual 2014. Memoria de Responsabilidad Corporativa. Madrid, $67 \mathrm{p}$.

Norwegian Meteorological Institute (2013) Extreme Weather Events in Europe: preparing for climate change adaptation. Norwegian Academy of Science and Letters, Oslo, $136 \mathrm{p}$.

Olcina Cantos, J. (2012) "Turismo y cambio climático: una actividad vulnerable que debe adaptarse", Investigaciones Turísticas, 4, 1-34.

Olcina Cantos, J. (2014) "El turismo ante el cambio climático", en Turismo y Territorio. Innovación, renovación y desafíos (Lopez Palomeque, F. y Cànoves Valiente, G., eds.). Tirant Lo Blanch, Valencia. 615-659.

Olcina Cantos, J. (2014) "Cambios en la consideración territorial, conceptual y de método de los riesgos naturales", en Enfrentados a un destino adverso. De las calamidades naturales hacia las ciencias cindinicas (Calvo García-Tornel, F., Ed.) Ed. Geo-crítica. Universidad de Barcelona. 47-68. 
Olcina Cantos, J., Saurí Pujol, D. y Vera Rebollo, J.F. (2014) "Turismo, cambio climático y agua: escenarios de adaptación en la costa mediterránea española"" en Libro jubilar en homenaje al profesor Antonio Gil Olcina, Alicante, Servicio de Publicaciones de la Universidad de Alicante, 171-193.

Olcina Cantos, J. y Miró-Perez, J.J. (2016) "El clima, recurso básico del turismo alicantino. De la valoración del clima invernal al aprovechamiento intensivo del clima estival", Canelobre, 66. Alicante, Instituto Alicantino de Cultura Juan Gil-Albert. 19-37.

Organización Mundial del Turismo (2015): Panorama OMT del Turismo Internacional, edición 2015. Madrid, OMT, 16 p.

Quereda Sala et alii (2001) Nuestro porvenir climático, ¿Un escenario de aridez?. Universitat Jaume I, Castellón, 224 p.

Rico-Amoros, A., Olcina-Cantos,J. and Sauri, D. (2009): "Tourist Land Use Patterns and Water Demand. Evidence from the Western Mediterranean”, Land Use Policy, 26, 493501.

Rico Amorós, A., Sauri Pujol, D., Olcina Cantos, J. y Vera Rebollo J.F. (2013) "Beyond Megaprojects?. Water Alternatives for Mass Tourism in Coastal Mediterranean Spain" Water Resources Management, 01/2013; 27(2). DOI: 10.1007/s11269-012-0201-3.

RIU Hotels and Resorts (2014) Achievements 2014. Corporate Social Responsibility. 30 p.

Roselló, J. (2011) "España, Turismo y cambio climático", Economistas n 127, Madrid, 28-34.

Sauri, D., Olcina, J., March, H., Martín-Vide, J., Vera, F., Padilla, E. and Serra-Llobet, A. (2013) "Tourism, Climate Change and Water Resources: Coastal Mediterranean Spain as an Example", in European Climate Vulnerabilities and Adaptation: A Spatial Planning Perspective, Publisher: John Wiley \& Sons, Ltd, Editors: Philipp Schmidt-Thomé, Stefan Greiving, 231-252.

Schmidt-Thomé. P. and Klein, J. (ed.) (2013) Climate Change Adaptation in practice. WileyBlackwell, Oxford, 327 p.

Schneider, E. (2010) "Floodplain Restoration of Large European Rivers, with Examples from the Rhine and the Danube", in Martina Eiseltová (ed.) Restoration of Lakes, Streams, Floodplains, and Bogs in Europe, Wetlands: Ecology, Conservation and Management, 3, 185-223.

Scott, D. (2006) "Climate change and sustainable tourism in the 21st century", in Cukier, J.(ed.) Tourism Research: Policy, Planning, and Prospects . Waterloo. Department of Geography, University of Waterloo, 175-248.

Skiliris, N., Sofianos, S., Gkanasos, A., Mantziafou, A., Vervatis, V., Axaopoulos, P. y Lascaratos, A. (2012) "Decadal scale variability of sea surface temperature in the Mediterranean sea in relation to atmospheric variability". Ocean Dynamics, 62, 13-30.

Vera Rebollo, J.F. y Baños, C.J. (2010) "Renovación y reestructuración de los destinos turísticos consolidados del litoral: las prácticas recreativas en la evolución del espacio turístico", Boletín de la Asociación de Geógrafos Españoles, nº 53, 329-353.

Vera, J.F.; Rodríguez. I, y Capdepón, M. (2010). "Reestructuración y competitividad en destinos maduros de sol y playa: la renovación de la planta hotelera de Benidorm". En XIII Congreso Internacional de Turismo Universidad y Empresa: renovación de destinos turísticos consolidados. 
World Economic Forum (2015): The Travel \& Tourism Competitiveness Report 2015. Disponible en:

http://www3.weforum.org/docs/TT15/WEF_Global_Travel\&Tourism_Report_2015.pdf World Travel and Tourism Council (2009) Leading the Challenge on Climate Change. London. World Travel \& Tourism Council. 